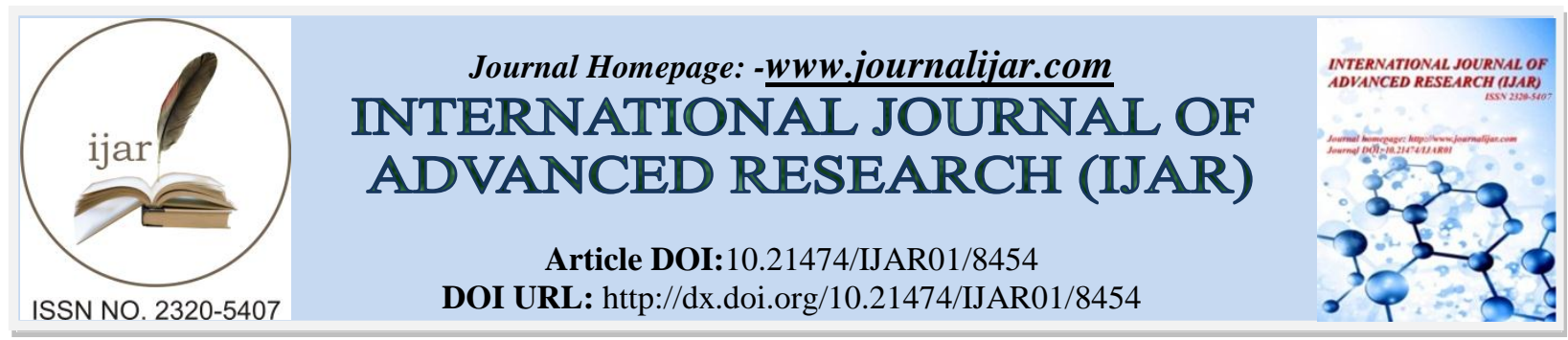

RESEARCH ARTICLE

\title{
ICU ADMISSIONS IN OBSTETRICS: ANALYSIS OF INDICATIONS , INTERVENTIONS AND MORTALITY IN A TERTIARY CARE CENTRE.
}

\author{
Preeti Sharma $^{1}$, Deepti Rana ${ }^{1}$, Ashok Verma ${ }^{2}$, Nikita Gandotra ${ }^{1}$ and Sabia Rashid ${ }^{1}$.
}

1. Senior Residents, Deptt of Gynaecology and Obstetrics, Dr RPGMC Tanda.

2. Asociate Professor, Deptt of Gynaecology and Obstetrics, Dr RPGMC Tanda.

\section{Manuscript Info}

Manuscript History

Received: 20 November 2018

Final Accepted: 22 December 2018

Published: January 2019

Key words:-

ICU, Haemorhage.

\section{Abstract}

Background: Obstetrics emergencies pose a major challenge to obstetricians and should be managed by multidisciplinary team in ICU. Objectives: To analyse the demographic pattern, cause of admission ,intervention and maternal outcome in obstetric patients admitted in ICU.

Material and methods: A retrospective observational analysis of 58 obstetric patients admitted and managed in ICU was done. The parameters studied were cause of ICU admission, intervention and outcome of such patients.

Results: Only 58 patients were admitted to ICU over a period of two years which constitutes $0.29 \%$ of all the deliveries and $0.27 \%$ of all emergency obstetric admissions. The main obstetric indications for ICU admissions were ectopic pregnancy $(25.86 \%)$, postpartum haemorhage $(22.41 \%)$ followed by hypertensive disorders(20.68\%), antepartum haemorhage $(6.89 \%)$ and medical disorders $(5.17 \%)$ The mortality rate among the women admitted in ICU was $8.62 \%$.

Copy Right, IJAR, 2017,. All rights reserved.

\section{Introduction:-}

Maternal mortality is widely acknowledged as a general indicator of the overall health of a population, of the status of women in society. Globally, about 800 women die everyday of preventable causes related to pregnancy and childbirth; 20 percent of these women are from India. The maternal mortality rate in India according to the sample registration system(SRS) data released by the office of Registrar General of India declined to 130 in 2014-16 from 167 in 2011-2013. Obstetric emergencies are leading cause of maternal mortality and morbidity. These emergency conditions should be managed in a well equipped, dedicated obstetric intensive care unit(ICU) for better maternal and fetal outcomes(1).The incidence of ICU admission in obstetrics in developed countries is 2-4/1000 deliveries, where as in the developing nations it is as high as 2-13.5/1000deliveries(2) Hypertensive disorders and obstetric haemorrhage are the two commonest risk factors for ICU admission.(3).The other risk factors are sepsis, cardiac disease and severe anaemia.(3,4,5). The common non obstetric indications are trauma, cerebrovascular accidents, renal disordes, anaesthetic complications. Hence, the present study was conducted to evaluate the incidence, indications, interventions and outcome of obstetrics patients admitted in ICU of a tertiary care centre.

Corresponding Author:-Preeti Sharma.

Address:-Senior Residents, Deptt of Gynaecology and Obstetrics, Dr RPGMC Tanda. 


\section{Methods:-}

This retrospective cohort study was conducted in surgical ICU of Dr RPGMC Tanda, Kangra, Himachal Pradesh. The study population comprised of all obstetric admissions to the ICU over a period of 2 years from January 2017 to December 2018. Data was collected retrospectevily from an ICU database of all obstetrics patients admitted in ICU. Individual patient parameters like demographic dimensions, age, parity, gestational age and indication for ICU admission were noted. The ICU interventions in terms of mechanical ventilation, use of ionotropes were also tabulated. All patients were followed till discharge from the hospital or till death. The data were analysed statistically by using percentage and was compared with total number of ICU admission, total number of deliveries over that period of time.

\section{Results:-}

Total number of ICU admissions were 740 over this 2 year study period. Emergency obstetric admissions were 21109 and total number of deliveries were 19611.Only 58 patients were admitted to ICU which constitutes $0.29 \%$ of all the deliveries and $0.27 \%$ of all emergency obstetric admissions. Most of the patients were in 20-30 year age group $(72.41 \%)$, only $2(3.44 \%)$ were less than 20 years of age. There were $40(68.96 \%)$ multigravida and $18(31.03 \%)$ primigravidas. The main obstetric indications for ICU admissions were ectopic pregnancy $(25.86 \%)$, postpartum haemorhage $(22.41 \%$ ) followed by Hypertensive disorders(20.68\%), antepartum haemorhage (6.89\%) and medical disorders(5.17\%).Other indications were rupture uterus(5.17\%), perpueral sepsis(3.44\%), severe anaemia $(1.72 \%)$ and molar pregnancy $(1.72 \%)$.The maternal mortality rate among the women admitted in ICU was $8.62 \%$.The main cause of maternal death was haemorrhage $(60 \%)$ followed by hypertensive disorder(20\%) and medical disorders $(20 \%)$

Table 1:-Distribution of patients according to age.

\begin{tabular}{|l|c|c|}
\hline \multicolumn{1}{|c|}{ Number } & \%age \\
\hline$<20$ & 2 & 3.44 \\
\hline $20-30$ & 42 & 72.41 \\
\hline$>30$ & 14 & 24.13 \\
\hline
\end{tabular}

Table 2:-Distribution of patients according to parity.

\begin{tabular}{|c|c|c|}
\hline Parity & Number & \%age \\
\hline Primigravidae & 18 & 31.03 \\
\hline Multigravidae & 34 & 58.62 \\
\hline Grand Multi & 6 & 10.34 \\
\hline
\end{tabular}

Table3:-Distribution of patients according to period of gestation at admission.

\begin{tabular}{|l|c|c|}
\hline Period of gestation & Number & \%age \\
\hline Antepartum & 32 & 55.17 \\
\hline Postpartum & 26 & 44.82 \\
\hline
\end{tabular}

Table 4:-Indication for ICU admission.

\begin{tabular}{|l|c|c|}
\hline \multicolumn{1}{|c|}{ Indication } & Number & \%age \\
\hline Ruptured Ectopic & 15 & 25.86 \\
\hline APH & 4 & 6.89 \\
\hline PPH & 13 & 22.41 \\
\hline Rupture Uterus & 3 & 5.17 \\
\hline Hypertensive disorders & 12 & 20.68 \\
\hline Medical disorders & 3 & 5.17 \\
\hline Puerpural Sepsis & 2 & 3.44 \\
\hline Seveare Anaemia & 1 & 1.72 \\
\hline Post MTP complications & 2 & 3.44 \\
\hline Molar pregnancy & 1 & 1.72 \\
\hline Post Cesarean complication & 2 & 3.44 \\
\hline
\end{tabular}


Table 5:-ICU intervention.

\begin{tabular}{|l|c|c|}
\hline Intervention & No of cases & \%age \\
\hline Mechanical ventilation products & 33 & 56.89 \\
\hline $\begin{array}{l}\text { Blood/Blood } \\
\text { transfusion }\end{array}$ & 28 & 48.27 \\
\hline Ionotropes & 35 & 60.34 \\
\hline Antihypertensive & 12 & 20.68 \\
\hline Anticonvulsant & 11 & 18.96 \\
\hline Surgical intervention & 2 & 3.44 \\
\hline
\end{tabular}

Table 6:-Maternal Outcome.

\begin{tabular}{|l|c|l|}
\hline Outcome & No of cases & $\%$ age \\
\hline Improved & 49 & 84.48 \\
\hline Reffered to higher centre & 1 & 1.72 \\
\hline Expired & 5 & 8.62 \\
\hline LAMA & 3 & 5.17 \\
\hline
\end{tabular}

Table 7:-Cause of maternal mortality in ICU.

\begin{tabular}{|l|c|l|}
\hline Cause & No of cases & \%age \\
\hline Haemorhage & 3 & 60 \\
\hline Hypertensive disorder & 1 & 20 \\
\hline Medical disorder & 1 & 20 \\
\hline
\end{tabular}

\section{Discussion:-}

Management of the critically ill obstetric woman at an ICU is a unique challenge to ICU Physicians and obstetricians. The percentage of obstetric population requiring admission to the ICU is different in different countries based on the socioeconomic status, criteria for ICU admission, availability of ICU beds, and availability of a high dependency unit. It ranges from 0.08 to $0.76 \%$ of deliveries in developed countries [ $\underline{3}$ ] and 0.13 to $4.6 \%$ in developing countries [6]. In our study during the two year period, obstetric admissions to the ICU represented $0.29 \%$ of all deliveries and $0.27 \%$ of all emergency obstetric admissions. $44.82 \%$ of women admitted to ICU were in postpartum period. In the study by Yuel Veronica et al. 50\% of ICU admissions were in postpartum period. The main obstetric indications for ICU admissions were ectopic pregnancy(25.86\%), postpartum haemorhage $(22.41 \%)$ followed by Hypertensive disorders(20.68\%), antepartum haemorhage $(6.89 \%)$ and medical disorders $(5.17 \%)$. The major indications of admission were hypertensive disorder of pregnancy i.e. $42 \%$ followed by obstetric haemorrhage i.e. $16 \%$ in study conducted by Saha $\mathrm{R}$ et al(9)

28(48.2\%) patients required inotropic support, 33(56.89\%) mechanical ventilation for varied duration and $35(60.34 \%)$ patients were on ionotropes. Pattnaik et al reported as high as $41 \%$ of patients requiring mechanical ventilation(10) .The most common indications for MV were acute respiratory failure and hemodynamic instability The mortality in these patients is high and ranges from 0 to $4.9 \%$ of ICU admissions in developed [3] and 2-

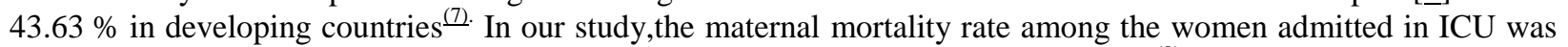
$8.62 \%$. Saha R etal. Reported $6 \%$ of maternal mortality rate in obstetric ICU patients ${ }^{(9)}$ The main cause of maternal death was haemorrhage(60\%) followed by hypertensive disorder(20\%) and medical disorders(20\%). Pattnaik et al in their study observed that obstetric hemorrhage was major cause of mortality in ICU patients and accounted for $55.5 \%$ mortality $^{(10)}$

\section{Conclusion:-}

Our study concludes that $0.29 \%$ of all the deliveries required ICU care which is quite comparable to western world. Hypertensive disorders and obstetric haemorrhage are the most common obstetric reasons for admission.. The mortality rate was $8.62 \%$ with major obstetric haemorrhage topping the list. It also concludes that a close follow up of high risk pregnancy and an optimal stabilization of their condition before intervention improved the outcome of these patients. Majority of conditions that contribute to ICU admission are preventable.To improve the maternal outcome a team effort of all disciplines is required. 


\section{References:-}

1. Zeeman GG, Wendel GD, Cunningham FG.A blueprint for obstetric critical care. Am J Obstet Gynecol. 2003;188:532-536. Doi:10.1067/mob 2003.95[pubmed]

2. Pollock W, Rose L, Dennis CL. Pregnant and postpartum admissions to the intensive care unit: A systematic review. Intensive Care Med. 2010;36:1465-74.

3. Baskett TF, O' Connell CM.Maternal critical care in obstetrics. J Obstet Gynaecol Can. 2009;31(3):218-221. Doi 10.1016/S1701-2163(16)34119-6 [PubMed]

4. .Jain M, Modi JN. An audit of obstetric admissions to intensive care unit in a medical college hospital of central India: lessons in preventing maternal morbidity and mortality. Int J Reprod Contracept Obstet Gynecol. 2015; 4(1): 140-145.

5. Small MJ, James AH, Kershaw T, et al.Near miss maternal mortality: cardiac dysfunction as the principal cause of obstetric intensive care unit admissions. Obstet Gynecol. 2012; 119: 250-255. doi : 10.1097/AOG. 0b0131824265c7

6. Ibrahim IA, Rayis DA, Alsammani MA, et al. Obstetric and gynecologic admissions to the intensive care unit at Khartoum Hospital, Sudan. Int J Gynecol Obstet. 2015;129(1):84. doi: 10.1016/j.ijgo.2014.10.019

7. Bandeira AR, Rezende CA, Reis ZS. Epidemiologic profile, survival, and maternal prognosis factors among women at an obstetric intensive care unit. Int $\mathbf{J}$ Gynaecol Obstet. 2014;124(1):63-66. doi: 10.1016/j.ijgo.2013.07.015.

8. Yuel V. Irene, Kaur Vaneet, Kaur Gurvinder, Andappam Arun, Afzal Lalita. Critical care in obstetrics- scenario in a developing country. J Obstet Gynaecol India. 2008 May-Jun;58(3):217-20.

9. Saha R, Shakya A Study of obstetric patients admitted to Intensive Care Unit (ICU) at Kathmandu Medical College Teaching Hospital Journal of Kathmandu Medical College, Vol. 2, No. 4, Issue 6, Oct.-Dec., 2013

10. Pattnaik T,Samal S.Obstetric admissions to the intensive care unit: a five year review.Int J Reprod Contracept Obstet Gynecol. 2015 Dec;4(6):1914-1917. 